\title{
Shaping the environmental consciousness of international engineering students in class Russian language
}

\author{
Irina Kondratieva ${ }^{1,{ }^{*}}$, Tatiana Rogacheva ${ }^{1}$, Nadezhda Malina ${ }^{1}$ and Elena Vyshegorodskaya $^{1}$ \\ ${ }^{1}$ Don State Technical University, 1, Gagarina square, 344000, Rostov-on-Don, Russia
}

\begin{abstract}
The article is devoted to the issues of forming ecological consciousness of foreign students of technical universities at the classes on Russian as a foreign language. The article gives definition of ecological consciousness; methods of formation of competence of a future engineer as a specialist, who is aware of the necessity to observe ecological principles in his work, are studied. The statistics of student polls on environmental problems is given. Reading texts on environmental topics, preparation of monologic statement on the theme "Environmental problems of our time", holding a discussion club, preparation of scientific reports on environmental issues, participation in an imitation role-playing game, participation in events of the university, devoted to environmental protection, help to realize the importance of the problem and the need to solve it in the professional activity of a technical specialist.
\end{abstract}

\section{Introduction}

Russian educational standards of the new generation require the introduction of an environmental component as one of the competencies of an agricultural engineer. Researchers study the diagnosis of the formation of environmental competence, methods to improve its level $[1,2]$.

The researchers note the different approach to solving environmental problems in Europe, America and Asia [3, 4]. Rapid development of industry of the People's Republic of China (PRC) has led to a sharp exacerbation of the environmental situation in the country. Therefore, the description of the behavior of students at the Chinese University and their knowledge of ecological civilization is of certain interest for understanding the systems of ecological education and upbringing in universities. The national strategy of environmental protection in China has been changed to ecological civilization. Accordingly, courses have been organized for students and educational programs have included material on environmental protection, primarily for agricultural engineers [5].

Population growth on the planet Earth entails an increase in the consumption of agricultural products produced by agro-industrial enterprises. Unreasonable capacity building of enterprises has an adverse impact on soil, water resources and air. Pedagogical

* Corresponding author: Irina-kondratieva@yandex.ru 
models that form the moral and ecological level of consciousness make it possible to reach a certain level of engineering education [6].

Many authors studying the problem of environmental culture have noted the need to involve students in design and creative activities that stimulate the development of both primary skills and the development of consciousness itself. Environmental attitudes, according to some authors, play an important role in the process of predicting environmental behavior $[7,8]$.

All the above confirms the relevance of research methods and techniques used in Russian language classes to form the ecological consciousness of students from all over the world.

At the Don State Technical University (DSTU) on lessons on Russian language the essential attention is drawn to development of system of scientific views on nature problems, knowledge and value ideas about necessity of cardinal improvements of nature protection activity.

For over half a century, the Don State Technical University (DSTU) has been training specialists for foreign countries in Europe, Asia, Africa and Latin America. In 1977, the Department of Russian for foreign students, most of whom were students of the Faculty of "Agricultural Machinery", was founded, now the Faculty of "Agro-industrial". In 70-80s students from European countries - GDR, Hungary, Poland, Czechoslovakia studied at the faculty. Foreign students - future designers of agricultural machinery mastered the Russian language in order to understand and solve in details the proposed complex problems of design and technical use of powerful combines and other agricultural machinery. During the training of engineers, special attention was paid to the issues of ecology, the impact of machinery on soil, minimizing environmental losses, the formation of environmental awareness of future specialists.

\section{Main part}

The concept of "ecological consciousness" in the $80 \mathrm{~s}$ is defined by the Ecological Encyclopedic Dictionary as a deep understanding of the inseparable connection between man and nature, the dependence of human well-being, the integrity of the natural habitat of man on anthropogenic changes in the environment of life on Earth, beyond the adaptive capacity of man as a biological species. Ecological consciousness - part of ecological education [9].

The realities of today's life, the practice of the Russian and world system of personnel training in higher education institutions, the introduction of new educational standards determine the need to form the ecological consciousness of a technical university graduate as an indicator of the competence of a future engineer. The existing national project "Ecology" sets serious tasks for graduates of Russian universities. Foreign students studying at DSTU begin to show a keen interest in environmental issues thanks to the policy of the university and faculty management, the Department of "Life Safety" on the implementation of various activities aimed at understanding the severity of the environmental crisis on the planet, and the work of teachers of the Department of "Russian as a foreign language" to form professional competence in Russian.

The professional competence is created in the process of influence on the trainee according to the certain standard and achievements of the necessary level of knowledge and skills. It is a controlled process of formation of professionalism, education and selfeducation of a specialist, it is formation of new consciousness, creative attitude to activity, understanding of consequences of the impact of technical progress on the environment [10].

It is necessary to concretize and formulate the principles of formation of professional competence of a specialist. 
ecology", which gathered more than a thousand participants in 2020, has become a manifesto of the activity of teachers and students of the supporting university and a kind of a result of the huge work carried out at the university on the popularization of environmental issues, practical implementation of tasks set by the rector, on the formation of environmental consciousness of future specialists, in which the greatest attention is paid to engineering personnel as specialists directly facing the risks posed by human activity to the environment. Throughout the training students are involved in many activities that contribute to the formation of skills in caring for nature. An eco-unit has been established at the university, whose team is preparing data on environmental pollution "Our ecological footprint". Volunteers of the eco unit made a list of cases available to everyone to save the Earth. Several issues of the student magazine "Plus One" are devoted to environmental problems. The Green Resources section of the magazine offers readers addresses of websites with up-to-date information on the environmental situation in the region and the country, as well as informs about environmental events in Rostov-on-Don: recyclemap.ru a convenient map of separate waste collection, the site contains information on all points of reception of waste paper, plastic, metal, clothes, equipment and batteries; ar.rostov-gorod.ru - the portal "Active Rostov citizen" provides information on the environmental situation in the region as well as offer their own; ecodon.dspl.ru - on this site you can find ecological maps of the Rostov region, information about flora and fauna, thematic calendar, news, announcements of events; Rostov.gks.ru - the official site of the Federal State Statistics Service of the Rostov region contains current information about the population, living standards and the state of the environment. A lot of work is carried out by the Information Center on Nuclear Energy of DSTU, organizing presentations of modern eco-technologies. DSTU students carry out work on restoration of what was destroyed by a man, develop modern technologies designed to reduce the impact on the surrounding world. Even the usual events surprise foreign students. They are interested in collecting waste paper, teaching separate waste collection, planting greenery. But the main thing in this work is to solve engineering and design problems.

The Interagromash exhibition is organized annually by the Faculty "Agro-industrial" DSTU. The exhibition demonstrates not only the technical achievements of the Russian agro-industrial sector, but also environmental developments [14 -17].

A person's speech is directly related to their consciousness. The individual and social in human consciousness are interrelated characteristics. A specific language consciousness is a socially deterministic phenomenon.

During the whole process of teaching foreign students under the guidance of a Russian teacher study topics related to environmental problems of our time, explore scientific approaches to solving these problems. According to the State Standard for Russian as a Foreign Language, one of the topics for study and discussion is "Man and Environment" and the section of the textbook is called "Planet Earth - our common home" [18]. Students read the texts: "Green Cross" dedicated to the creation of an ambulance for the "sick" nature, "World of Ocean Jacques Cousteau" about the famous French explorer of the underwater world, ecologist and traveler, "Singing Whales" about the death of whales in Canada. Students are invited to give answers to general questions (e.g. "Why have many plants and animals disappeared on Earth?", "Why is the environmental crisis now often talked about and written about?") and discuss the problematic situation: "The air pollution process continues. Today 20 billion tons of coal are burned every year and 300 billion tons of carbon monoxide and other harmful substances are released into the atmosphere. The polluted air of large cities affects human health and causes new, previously unknown diseases. - Under what condition do you think the air pollution process can be reduced?

In the manual on teaching scientific style of speech by teachers of the department included articles on ecology: "Our common problems", "Earthquakes". Students read texts 
on environmental problems in Russia, prepare reports on the nature of their countries, the state of water, air, forests. Before studying this topic, the teachers offer the students a questionnaire. According to the results of the survey, students find out what threat to the planet Earth and its population they consider the most dangerous. It should be noted that students often do not give priority to environmental problems before studying the texts and participating in university events. Leaders are terrorism, wars, nuclear disaster and even space threat. Foreigners are struck by information on riches of Russia (fresh water reserves in lake Baikal, Russian forests as "light" planets). It is difficult to understand that even earthquakes can be caused by human activity. Students from Africa, Asia, Latin America do not realize the urgency of the problem. There are so many social problems in their states that environmental issues are relegated to the background. Of the 250-300 people surveyed each year, on average, only 3 for every 10 respondents consider the environmental crisis to be particularly dangerous. Understanding necessity of formation of ecological consciousness of the future engineers, teachers of Russian as foreign language apply various methodical receptions for creation of conditions for formation of ecological thinking.

The fundamental principle of environmental education is to understand that environmental consciousness will only become truly conscious when man understands his organic unity with nature, his possibilities for destruction, creation and regulation of this unity. The environmental consciousness of students should be fixed in the belief that each person is not only a unique person, but also a part of humanity associated with nature.

The next principle of environmental education is the focus on understanding that man is the carrier of consciousness. This condition the self-knowledge of a person, determines the meaning of life - making an individual contribution to the collective Reason. These global goals are divided into certain components that are formed at certain stages of education.

Here, first of all, such goals are achieved as the formation of a certain image of the outer world in which elements of benefit and harm, stability and dynamics are combined in dialectical unity, etc. The next goal is to form the unity of ecological worldview and ecological behavior, the need to combine "word and deed". Further, the work is based on the formation of active effective expectation, knowledge about the ability of the subject to successfully influence in order to get the desired result.

The next principle is based on the fact that the values of environmental education are quite abstract, but the education of environmental consciousness should go from simple to complex. And at each stage, the abstract and concrete should be combined. In other words, to supplement the phenomenological world with the world of concepts, the concept of "cannot", which reflects a person's attitude to this world with "a concept that becomes the essence of his relationship with the environment".

Environmental education is based on a personal approach, taking into account all the aggregate characteristics of the individual and his or her environment.

Communication with nature is of great importance. Communication is not only active, creative, but also passive, contemplative. The experience of contacts with nature allows not only to realize the problems facing society in their generalized, abstract form, but also to formulate these problems by oneself.

Students prepare reports in Russian on environmental topics for presentation in a discussion club, at a scientific conference or for a business role-playing game.

Participants of the discussion club carry out joint research using educational texts, Internet materials, scientific articles, films about modern environmental problems, develop a slide - presentations, make presentations. Moving from one stage of research to another, they gradually increase the amount of material involved, actively using the Internet to find the right information, expand their active and passive vocabulary. International students learn to describe and analyze selected material, formulate conclusions and answer questions 
during scientific discussions. Regular discussion of specific scientific information with a Russian teacher and other participants of the discussion club helps to overcome communicative barriers in scientific communication, forming skills of public speaking. Activities of the discussion club combine communicative, cognitive, transformative, research, educational and other activities.

The use of this method allows to develop skills of choice of type of discourse corresponding to its communicative purpose and providing realization of communicative intentions of the foreign student, helps to create real discourse according to sphere and a situation of communication, provides understanding and interpretation of the information on the basis of knowledge of a situation, and also on background knowledge of an ecological situation in Russia, in the homeland of the student, in the world.

Understanding the peculiarities of scientific style of speech is a component of the culture of thinking, which is determined by a high level of formation of such basic characteristics as independence, productivity, flexibility, criticality, logicality.

Having set the goal of forming the skills and abilities of written and oral communication in Russian in the research sphere, the teacher of Russian as a foreign language does not limit students to the interpretation, analysis and creative search of materials only on the specialty of the student or correction of works on the professional subject of research. The task of a Russian teacher is to prepare students to speak at scientific and practical conferences, write reports and scientific articles on environmental topics [19].

The organization of such work is carried out in accordance with the following requirements:

1. Students should choose the field of research in accordance with their interests in the study of environmental problems and topics proposed by scientific leaders.

2. Students should perform analytical-synthetic processing of the information selected from the text source and transfer it in the form of a plan, thesis, annotation and abstract, observing all basic requirements for the genre of scientific research.

3. Students should use language tools that are specific to the scientific style of speech.

Preparation of the report at the seminar, round table, scientific conference envisages the following sequence of main stages of work organization:

- Selection of the subject area of scientific research, identification of research objectives, and definition of tasks to be accomplished;

- recommendations of the scientific supervisor for the definition of the research area and for the selection of the topic in Russian;

- the validity of the chosen subject matter;

- Conducting a meaningful analysis of the research area: identifying key concepts, defining sustainable relationships, establishing the boundaries of scientific research;

- filling the knowledge base using all information sources;

- search for articles on the research topic;

- annotating and abstracting articles from scientific industry journals;

- consideration of standardization of all elements of a scientific work: language, composition, bibliographic apparatus.

The tasks proposed by the supervisor, designed for a conscious approach to the material under study, stimulate the mental activity of students, contribute to the development of their skills of accurate linguistic and stylistic analysis of the expression of scientific thought, skills to build logical reasoning and convincing system of argumentation. As a result, this increases the language competence of students, the possibility of adequate expression of their thoughts in Russian, contributes to the development of skills of written annotation and referencing of scientific literature on the topic of the study.

In the process of this activity, the following important skills and abilities for the future professional are most successfully developed among the participants: 
Table 2. Important skills and abilities.

\begin{tabular}{|l|l|}
\hline \multicolumn{1}{|c|}{ Important skills and abilities } \\
\hline Communicative & $\begin{array}{l}\text { the ability to initiate effective interaction with partners (enter into } \\
\text { a dialogue, ask questions) }\end{array}$ \\
\cline { 2 - 3 } ability to lead a discussion \\
\cline { 2 - 2 } ability to assert their point of view \\
\cline { 2 - 2 } the ability to find a compromise \\
\hline Information & $\begin{array}{l}\text { ability to initiate effective interaction with partners (enter into a } \\
\text { dialogue, ask questions; - ability to defend your point of view }\end{array}$ \\
\cline { 2 - 2 } ability to find a compromise \\
\hline $\begin{array}{l}\text { development of computer skills, work with online translation } \\
\text { dictionaries; Russian explanatory dictionaries }\end{array}$ \\
\cline { 2 - 2 } use the Internet to find meaningful information \\
\cline { 2 - 2 } participation in scientific conferences, preparation of presentations \\
\hline & $\begin{array}{l}\text { the ability to generate ideas on their own, search for a way of } \\
\text { action, attracting knowledge from various sections of } \\
\text { environmental science and Russian language }\end{array}$ \\
\hline ability to search for missing information independently \\
\cline { 2 - 2 } & the ability to make hypotheses \\
\hline
\end{tabular}

To study and consolidate the topic "Man and the Environment" there is a discussion club for second year students, as students have the necessary level of Russian language skills and professional knowledge. The Discussion Club provides an opportunity to interest students and increases their motivation. Reading texts on the environment, the figures testifying to the environmental crisis help them to enter the problem, and the discussion club helps them to defend their point of view, to offer solutions to problems not as ordinary people, but as future engineers. The learning objectives of the topic include stimulating students' speech activities in monolog and dialogic forms; mobilizing and developing means of speech expression; and strengthening discussion skills. Professional goals include using professional knowledge to address environmental issues. Educational goals include the formation of students' teamwork skills, the education of environmental consciousness and aesthetic perception of the environment by students of technical university.

In the lessons on Russian as a foreign communication as an educational strategy is implemented in such a form of educational process organization as an imitation roleplaying game, which allows to solve the speech problems of learning, motivate students to conduct problem organization of educational material, use authentic material and communicative valuable phrases, that is, those that are used in communication, rather than just correct from the point of view of language.

The game introduces constant novelty, use of heuristic approach, when arbitrary memorization and reproduction of the learner is excluded, when constant variation of all exercises, materials and conditions is ensured.

Traditional situational and role-playing learning has gained new understanding at the present stage. The principle of communicativeness requires a rethinking of some familiar concepts. The situation should be understood not as a set of extra-linguistic circumstances, but as a system of relationships of interlocutors reflected in their consciousness; situational awareness is the correlation of a statement with these relationships. The situation is not a segment of reality, but a speech activity itself, so it is characterized by such basic features of activity as pithiness, certain structure, etc. Speech units used in speech situations are presented as recordings of speech actions in natural situations, playback of speech situations by informants, associative experiment. Learning objectives, situational field (breadth of context) define a set of materials for each situation, the depth of its discussion. 
Speech situations in different spheres of communication are not homogeneous in their structure: in the social and domestic sphere they are monotopic, in the social and cultural sphere they are polytopic.

The organization of material for learning to communicate should be situationalthematic, that is, a number of situations related to different areas of communication, as well as a certain linguistic level of the grammatical structure, speech patterns, words, expressions, language formulas, etc. Such situational and thematic principle of organization of the communicative content of oral education is based on such factors as the factor of clarity of purpose, the factor of regularity, the factor of communication, the factor of play. The situation becomes a component of an imitation role-playing game.

Simulation role-playing games are widely used in the learning process, but many forms require careful preparation. A game is a type of activity in situations aimed at recreating and assimilating social experience and understanding of the mentality of the country of the studied language, in which not only the knowledge of the language is formed and improved, but also the understanding of the opponent's course of thought and selfmanagement of behavior. The concept of the game is disclosed in the prospectus, reflecting its general content and conditions of application, i.e. it specifies the subject and goals of the game, models of participants' activity.

In the scenario, the characterization of the object of the game is given, roles are established and substantiated, and the rules of the game are defined.

The game environment reflects principal decisions on the form of players' interaction in the course of the game (with the help of game objects, using documents, preparing presentation materials). The rules of the game are established for each game, which specifies the order of the game, the temporary order of conducting the game. To conduct the game an administrator is appointed who heads the group of game organizers. Then game teams are formed and roles are distributed among the players. To solve possible conflict situations and misunderstandings, as well as to help players, a group of experts is created.

The principles of the game construction include the following:

- clarity and simplicity of the construction (models) of the simulation-role game;

- completeness of topics and fragments of the game;

- possibility of further improvement and development of the role-playing game's constructions (models);

- use of ready-made developments, software products;

- visibility of all elements in solving the problem studied in the game.

The principles of the game are: full immersion of the participants of the simulation and role-playing game into the problems of the organizational system modeled in the game; gradual introduction of the participants into the experimental situation; uniform loading; plausibility of the experimental situation; participation of the teacher.

In the educational process, various modifications of the games are used: positional (implies finding out the position by means of the struggle of opinions); imitation-role games (imitating events, people's activity, positions and roles are determined in advance); plot games (reflecting positions and roles, but the plot remains the leader); situational games (have a tense action in a relatively short time); organizational-activity games (developing theoretical concepts and practical recommendations, carrying out the design of various activities); organizational and creative (developing the concept of a new activity).

According to the State Educational Standard for Russian as a Foreign Language one of the topics for study and discussion is "Man and the Environment" and a section of the training manual "Planet Earth - Our Common Home", so to study and consolidate this topic is developed an imitation role-playing game. The game is recommended for the students of the second year, because the necessary level of Russian language skills and professional 
knowledge has been formed. The imitation business game ensures the interest of students and increases their motivation for learning. The educational goals of the game include stimulation of students' speech activity in monolog and dialogical forms; mobilization and development of means of speech expressiveness; consolidation of skills of referencing and discussion. Professional goals include using professional knowledge to address environmental issues. The educational goals include the formation of students' teamwork skills, the education of environmental consciousness and aesthetic perception of the environment in students of technical university. A role-playing business game requires the development of a project, which determines the levels of preparation for this event. In the beginning the problem reflecting the substantial parties of game is called, the theme is defined: "Influence of scientific and technical progress on environment", "Modern manufacture and nature", "Ecology in mechanical engineering", "Threats to a planet the Earth", "Environment condition in the Rostov region", "Problems of environment in the countries of students", "Russian policy in the field of ecology", "Plans of the international cooperation in the field of ecology", "Measures of DSTU on formation of ecological consciousness of the future engineer [20].

According to the type of event (meeting at the plant, in the design office, scientific conference, briefing) the roles of students are defined: ecologist; engineer of agro-industrial complex; director of the plant; rector of the university preparing engineering personnel for the enterprise; press secretary; representative of the plant producing agricultural machinery; shareholders of the enterprise; investors; energy scientist; representatives of different countries - participants of the forum; businessmen, correspondents. A Russian language teacher determines the stages of the game and the direction of the discussion. According to the results of the game, the experts (a teacher with a group of students) are evaluated. The winners of the game are chosen.

The business game activates students' activity, develops environmental consciousness and creative thinking. After these activities to form environmental consciousness, a survey is conducted, which shows an increased level of understanding of the importance of environmental issues. Already 7 students out of 10 consider it necessary for an engineer to have environmental knowledge. Environmental education not only provides knowledge from the field of ecology, but is also an important link in environmental education for perspective specialists. It presupposes inculcation of high ecological culture, ability of careful attitude to natural resources. In other words, a new ecological consciousness and thinking should be formed among specialists of engineering and technical profile, the essence of which is that human being is a part of nature and nature preservation is the preservation of full human life.

The objects of reflection of ecological consciousness are ecological situation, social and environmental relations, social and environmental activities.

The content of environmental consciousness is disclosed through the concepts of "environmental relations" and "environmental activities". It includes the regularities of interaction between society and nature, as well as various empirical knowledge, views, traditions of this or that culture, which have an important ecological value, as well as the value moment in relation to nature, the system of regulatory principles of moral character.

The main component of the content of eco-consciousness is awareness of the value of life and the danger of its degradation, the need for its preservation, as well as awareness of the limited resources of nature consumed by humans; the need to abandon the domination of man over nature and establish a dynamic balance between natural systems and the human system; understanding the inevitability of the environmental crisis as a social crisis of a global nature; understanding the need to develop a global development strategy as a prerequisite for the existence of life. 
In the structure of ecological consciousness there are three relatively independent components: rational, sensual-emotional, behavioral-volitional, to which ecological knowledge, assessment of ecological situation and ecological behavior correspond.

For formation of favorable professional ecological consciousness it is necessary: corresponding laws, which make ecologically clean enterprises more profitable (for example, through tax benefits); public opinion (strengthening of ordinary ecological consciousness by its active formation by leaders of ecological movements, etc.); systematic educational work in the system of higher education, ecological education of future engineers, specialists, who will come to the agro-industrial complex with understanding of necessity to solve the problem of environmental problems, which is the main reason for creation of ecological consciousness.

\section{References}

1. G.G. Parfilova, A.M. Kalimullin, RProcedia - Social and Behavioral Sciences 131, 35 39 (2014) doi.org/10.1016/j.sbspro.2014.04.075

2. E.V. Kallas, T.P. Solovjeva, L.Yu. Minakova, Procedia - Social and Behavioral Sciences 200, 453-459 (2015) doi.org/10.1016/j.sbspro.2015.08.095

3. H. Doğan Südaş, E. Yaşa Özeltürkay, Procedia - Social and Behavioral Sciences 175, 176-184 (2015) doi.org/10.1016/j.sbspro.2015.01.1189.

4. I. Crumpei, S. Boncu, G. Crumpei, Procedia - Social and Behavioral Sciences 114, 461-465 (2014) doi.org/10.1016/j.sbspro.2013.12.730

5. R. Wang, R. Qi, J. Cheng, Y. Zhu, P. Lu, Journal of Cleaner Production 243, 118464 (2020) https://doi.org/10.1016/j.jclepro.2019.118464

6. N. Kuprina, S. Maslennikova, T. Lykova, O. Bormotova, Procedia - Social and Behavioral Sciences 214, 135-142 (2015) doi.org/10.1016/j.sbspro.2015.11.605

7. E.V. Asafova, Procedia - Social and Behavioral Sciences 191, 2329-2333 (2015) doi.org/10.1016/j.sbspro.2015.04.247

8. A. Keynan, O. Ben-Zvi Assaraf, D. Goldman, Studies in Educational Evaluation 41, 90-105 (2014) doi.org/10.1016/j.stueduc.2013.09.012

9. B. Johnson, J. Činčera, Studies in Educational Evaluation, 63, 94-101 (2019) doi.org/10.1016/j.stueduc.2019.08.003

10. K.S. Bakirova, S. Ainur, Procedia - Social and Behavioral Sciences 141, 543-545 (2014) doi.org/10.1016/j.sbspro.2014.05.094

11. M. Shahramanyan, V. Marchuk, I. Shrayfel, D. Chernyshov, B. Meskhi, O. Ananova, IOP Conf. Ser.: Mater. Sci. Eng. 680, 012026 (2019) https://doi.org/10.1088/1757$899 \mathrm{X} / 680 / 1 / 012026$

12. J.M. Polimeni, Ecological Economics 51(3-4), 287-293 doi.org/10.1016/j.ecolecon.2004.09.009.

13. E. Soares Oliveira, U. Paulino Albuquerque, A. Giuseppe Chaves Alves, M.A. Ramos, Journal of Arid Environments 167, $74-78$ (2019) https://doi.org/10.1016/j.jaridenv. 2019.05.001

14. E3S Web Conf., Innovative Technologies in Environmental Science and Education (ITESE-2019) 135, 01078 (2019) doi.org/10.1051/e3sconf/201913501078

15. S.I. Kambulov, I.V. Bozhko, A.V. Olshevskaya, MATEC Web of Conferences, ICMTMTE 2018, 05022 (2018) 
16. Yu.A. Ivanov, V.I. Pakhomov, S.I. Kambulov, D.V. Rudoi, MATEC Web of Conferences, ICMTMTE 2018, 05023 (2018)

17. B. Meskhi, Y. Bulygin, E. Shchekina, V. Maslensky, IOP Conf. Ser.: Earth Environ. Sci. 403, 012089 (2019) doi.org/10.1088/1755-1315/403/1/012089

18. J. Surjanti, A. Soejoto, D. Nugroho Seno, Social Sciences \& Humanities Open 2(1), 100009 (2020) doi.org/10.1016/j.ssaho.2019.100009

19. C.L. Spash, Ecological Economics 169, 106518 (2020) doi.org/10.1016/j.ecolecon

20. B.S. Zaunbrecher, B. Daniels, M. Roß-Nickoll, M. Ziefle, Energy Research \& Social Science 45, 91-106 (2018) doi.org/10.1016/j.erss.2018.07.015. 